\title{
Engineering Resistance Against Cotton Leaf Curl Kokhran Virus-Burewala Strain Using CRISPR-Cas9 System in Nicotiana Benthamiana
}

\section{Muhammad Hamza}

National Institute for Biotechnology and Genetic Engineering

Muhammad Zuhaib Khan

National Institute for Biotechnology and Genetic Engineering

\section{Roma Mustafa}

National Institute for Biotechnology and Genetic Engineering

Hira Kamal

National Institute for Biotechnology and Genetic Engineering

Aneela Hussain

National Institute for Biotechnology and Genetic Engineering

Shahid Mansoor

National Institute for Biotechnology and Genetic Engineering

Imran Amin ( $\square$ imranamin1@yahoo.com )

National Institute for Biotechnology and Genetic Engineering

https://orcid.org/0000-0003-3063-4103

\section{Research Article}

Keywords: CRISPR-Cas9, Cotton leaf curl Kokhran virus- Burewala strain, Cotton leaf curl Multan betasatellite, Intergenic region, Virus resistance

Posted Date: June 16th, 2021

DOI: https://doi.org/10.21203/rs.3.rs-604666/v1

License: (c) (i) This work is licensed under a Creative Commons Attribution 4.0 International License. Read Full License 


\section{Abstract}

Clustered regularly interspaced palindromic repeats (CRISPR) and associated Cas9 nuclease (CRISPRCas9) systems provide adaptive immunity to prokaryotes against infectious phage particles that can be engineered as a genome-editing tool. Guided by an RNA strand, the class II type II CRISPR-Cas9 system can be employed to provide resistance against plant DNA viruses. Here we describe an efficient CRISPRCas 9 genome editing system based on simultaneous targeting of the highly conserved intergenic region (IR) of the virus that can provide resistance against Cotton leaf curl Kokhran virus-Burewala strain (CLCuKoV-Bur) in Nicotiana benthamiana plants. The data revealed that upon infection, the transgenic plants harboring CRISPR-Cas9 and two gRNAs showed complete resistance against CLCuKoV-Bur/Cotton leaf curl Multan betasatellite (CLCuMB). All efforts failed to find the intact virus in CLCuKoV-Bur/CLCuMB challenged transgenic (OX:Cas9NB:IR) plants using either gene specific PCR primers or CLCuKoV-Bur as a probe in southern blot hybridization. Thus, our results have demonstrated an efficient CRISPR-Cas9 approach to engineer durable resistance against CLCuKoV-Bur in a model system. The implications of these findings are discussed.

\section{Introduction}

Geminiviruses are a group of plant viruses that inflict huge economic losses resulting in food insecurity particularly in the tropical regions of the world. These are single-stranded (ss) DNA ( 2.8 kb) viruses having unique twin icosahedral capsid [29]. The family Geminiviridae has recently been classified into nine genera on the basis of genome organization, host range, transmission vector and genome wide pairwise sequence identity [29]. Among these nine genera, begomoviruses constitute the largest genus of this family and are transmitted through whitefly (Bemisia tabaci; [9]) vector. New World (NW) begomoviruses are bipartite, i.e. having genomes consisting of two ssDNA components, referred to as DNA A and DNA B, of almost equal size ( $2.8 \mathrm{~kb})$. However, in the case of Old World (OW) begomoviruses, with a few exceptions, the vast majority are monopartite (single genomic component equivalent to DNA A), and most of these interact with ssDNA satellites referred to as betasatellites and alphasatellites [19].

Cotton leaf curl disease (CLCUD) is a very devastating and prevalent disease of cotton caused by monopartite begomoviruses associated with satellites [23]. This disease is a major limiting factor of cotton production and causes huge losses to the textile industry and other cotton related industries around the world. In the subcontinent, there were two major eras of cotton disease. The first was the Multan epidemic spanning 1988-1999. In 2001 the resistance was broken down by mutation in the virus causing the emergence of the Burewala strain [3]. This caused the new era with the Burewala epidemic spanning 2002 to the present. Currently, the most predominant virus infecting cotton in the field is Cotton leaf curl Kokharn virus- Burewala stain (CLCuKoV-Bur; [25]).

To date, various resistance strategies from a classical breeding and selection technique to modern hintonhnolnainal mothndc liko RNAi ar nrntain mediated resistance etc. have been devised to restrict Loading [MathJax]/jax/output/CommonHTML/jax.js 
geminivirus infection, but they often remain effective for only a short duration and sometimes become totally ineffective [22],[11]. This situation is further complicated by mixed virus infection [6]. Now, guided nucleases offer an avenue to direct site specific nucleases guided by an RNA transcript to target and cleave DNA and RNA viral genomes [13]. Cleavage of DNA molecules leads to frame shift mutations and knockouts via imprecise non-homologous end-joining repair (NHEJ) machinery or by precise homologydirected repair (HDR). Remaining unrepaired molecules are degraded by the cell repairing mechanism. Mutation in essential genes retard virus movement and dismantle its ability to move systemically [2]. This system can be employed to engineer resistance against begomoviruses by using its potential to perform site specific interference and editing.

The clustered regularly interspaced palindromic repeats (CRISPR) and associated Cas9 nuclease (CRISPR-Cas9) is part of an adaptive defense mechanism evolved in bacteria and archaea to defend itself against the invading pathogens [27]. The engineered CRISPR-Cas9 system has been successfully employed in eukaryotes and plants for site specific nuclease activity to create mutagenesis [15]. The Cas 9 nuclease is guided by a single guide RNA (sgRNA) molecule to cleave a target site preceded by a trinucleotide protospacer adjacent motif PAM (NGG) sequence [30]. With the help of a cell repair pathway, this system is able to mutate genomic sequence resulting in altered gene expression [20]. Various groups have reported the use of the CRISPR/Cas9 machinery to confer resistance against plant DNA viruses [12], [14].

In the present study, we have demonstrated virus interference via CRISPR/Cas9 by targeting a conserved region of a prevalent cotton infecting virus in Pakistan i.e. CLCuKoV-Bur with high efficiency. We have found that targeting the conserved Intergenic Region (IR) at multiple sites following a multiplexed approach showed no viral accumulation and abolished disease symptoms. Our results showed that CRISPR-Cas9 successfully blocked viral replication by cleaving the IR and demonstrating that the CLCuKoV-Bur then failed to replicate and move systemically. Our results provide important insights into the molecular underpinnings that will help to develop effective CRISPR-Cas9 based strategies for viral interference.

\section{Materials And Methods}

\section{Development of the construct targeting CLCuKoV-Bur}

Two different guide RNAs (gRNAs) were designed to target IR of CLCuKoV-Bur which contains the nonanucleotide sequence (TAATATTAC). A stretch of 128 nucleotides (nt) which consists of 53 nucleotides before and 66 nucleotides after the nonanucleotide sequence in the intergenic region (IR) were selected as a target. The gRNAs comprised of $20 \mathrm{nt}$, were designed and cloned using the available online web tool Benchling (www.benchling.com). The gRNAs were also screened for their potential offtargets using the same online tool. Primers were designed to amplify these gRNAs. Amplified sequences of gRNAs were ligated into the prlg107 vector (provided by Donald Danforth Plant Science Center) 
using specific primers (NN-F: $5 G G G \forall$ T GGAGACTGGATAC3', and $\mathbb{N}-R: 5$ CAACGAAGTACTTATAATAAGCG $3^{\prime}$ ). To confirm gRNAs in the vector, Sanger sequencing was performed using M13 F/R primers. Cas9 was confirmed using specific primers (Cas9-F: 5' TCGGAAGCTTATGGATAAGAAGTAC 3' and Cas9-R: 5' TCGGGAATTCTCAAACCTTCCTCTTCTT 3'). A schematic diagram of the construct is shown in Fig. 1.

\section{Development of transgenic Nicotiana benthamiana}

The construct harboring Cas9 and gRNAs cassette was transformed into agrobacterium via electroporation. Agrobacterium harboring the construct was transformed into $\mathrm{N}$. benthamiana explants (leaf discs). These explants were grown on MS medium provided with hormones and antibiotic selection under sterile controlled conditions. After development of roots and shoots they were transferred into soil and kept in a greenhouse under controlled conditions [18].

\section{Infectivity assay}

Confirmed transgenic plants (OX:Cas9NB:IR) were challenged with CLCuKoV-Bur (Acc. No. AM774294) alone and CLCuKoV-Bur/Cotton leaf curl Multan betasatellite (CLCuMB; Acc. No. AM774307). The plants were inoculated as mentioned earlier by Amrao et al. ([3]). At 25 days post inoculation (dpi), leaf tissue was collected and DNA isolated using a CTAB method [7]. DNA was ethanol purified and quantified using a nanodrop. A dilution of the DNA was used for the detection of virus through PCR using universal primers of Begomo F/R [26] and CLCV1/CLCV2 [10].

\section{Southern blot hybridization}

Total genomic DNA of $10 \mu \mathrm{g}$ concentration was resolved on a $1 \%$ agarose gel in $0.5 x$ TAE buffer for southern blot hybridization. DNA from the agarose gel was transferred to a nylon membrane (Hybond $\mathrm{N}^{+}$). A PCR DIG labeling kit (Roche, Switzerland) was used to develop the probe. PCR reactions were performed using universal primers of CLCV1/CLCV2 [10]. Blotting was performed as described by Sambrook et al. [21]. The hybridization signals were detected after treating blot with Nitro blue tetrazolium chloride (NBT) and 5-bromo-4-chloro-3-indolyl phosphate (BCIP; Thermo Scientific, USA).

\section{Results}

\section{Confirmation of gRNA in construct}

The presence of gRNA in the construct was confirmed through Sanger sequencing. The gRNAs having the sequence GAAATTCAAATTCCACTTTG for gRNA1 with PAM sequence of GGG corresponding to sequence 2710 to 2729 nucleotides (nt) of CLCuKoV-Bur. While the sequence of gRNA2 was GGGCCCACAAAAAAATCGCG with PAM sequence of CGG corresponding to sequence 13 to 20 nt of CLCuKoV-Bur. Out of five sequenced clones one clone (NN3) was selected because of the presence of both gRNAs in the sequence. The presence of Cas 9 was also confirmed using primers for the full length Cas9 seamence (two of them are shown in Fig. 2). 


\section{Transgenic plant development for viral interference via CRISPR-Cas9}

We have developed this system for targeting and editing DNA in a virus genome by over-expressing Cas 9 endonuclease in $\mathrm{N}$. benthamiana (OX:Cas9NB:IR) lines under control of the $35 \mathrm{~S}$ promoter. Two gRNAs, expressed under the Cestrum yellow leaf curling virus (CmYLCV) promoter were placed in the same binary vector which was used to develop OX:Cas9NB:IR transgenic lines. Five lines (T0) were obtained after the maturation of plants. Seeds were collected from them and grown. From each line, 12 plants were selected and grown. The transgenic lines were named as OX:Cas9NB:IR-1 to OX:Cas9NB:IR-5. All transgenic lines showed the same phenotype as that of wild type $N$. benthamiana plants. The process of transgenic plant development and analysis is shown in Fig. 3. The presence of transgene was confirmed via PCR using gene specific primers (NN-F/NN-R, Cas9-F/Cas9-R) which indicate presence of gRNA and Cas9 in the plants. A representative picture for confirmation of gRNAs is shown (Fig. 4).

\section{Infectivity assay}

Six plants from each of five transgenic lines (OX:Cas9NB:IR-1 to 5 ) and wild type $N$. benthamiana were challenged with CLCuKoV-Bur without a betasatellite or CLCuKoV-Bur with CLCuMB via agroinfiltration. All inoculated OX:Cas9NB:IR-1 to 5 lines and wild type plants were kept at $28^{\circ} \mathrm{C}$ in a greenhouse with $16-\mathrm{h}$ day length. A total of 72 plants were infiltrated. Among these, 36 plants ( 6 from each of five lines along with six control plants) were infiltrated with CLCuKoV-Bur alone and 36 plants ( 6 from each of five lines along with six control plants) with CLCuKoV-Bur/CLCuMB. Six wild type $N$. benthamiana control plants were also kept as healthy control and were not infiltrated. These plants were observed regularly for symptom development. After 13-15 days symptoms start appearing in wild-type $N$. benthamiana that included mild downward curling in case of CLCuKoV alone. However, in case of CLCuKoV-Bur/CLCuMB the downward curling was severe and yellowing of the leaves was also observed (Fig. 5-B). Very mild symptoms were observed in the case of OX:Cas9NB:IR-2 and OX:Cas9NB:IR-5 inoculated either by CLCuKoV-Bur or CLCuKoV-Bur/CLCuMB. However, plants from both lines recovered from those symptoms at $25 \mathrm{dpi}$ and showed the same behavior as that of other transgenic lines (Fig. 5-D and E). This suggests that the CRISPR system is working and possibly providing resistance to plants against CLCuKoV-Bur by not allowing it to replicate. Although the mild symptoms indicated that virus did replicate in OX:Cas9NB:IR-2 and OX:Cas9NB:IR-5 lines initially, successful establishment was aborted, and the plants recovered from the infection (Fig. 5). At $25 \mathrm{dpi}$, total genomic DNA was isolated from all these plants for various molecular assays. PCR was performed to check the presence of CLCuKoV-Bur in the challenged transgenic $N$. benthamiana lines. Universal primers for begomovirus i.e. Begomo F/Begomo R [26] were used to amplify $2.8 \mathrm{~kb}$ virus. No intact CLCuKoV-Bur was amplified from OX:Cas9NB:IR-1 to OX:Cas9NB:IR-6 (Fig. 6). CLCuKoV-Bur replicate via rolling circle replication (RCR) by hijacking plant machinery. RCA of inoculated transgenic plants was performed, and the product was digested with EcoRI, $B a m H I, X h o l$ and Hindll but no viral band of $2.8 \mathrm{~kb}$ size was observed which supported the observations from PCR amplification of the same samples using universal begomovirus primers. Rolling circle

Loading [MathJax]/jax/output/CommonHTML/jax.js argeting IR completely abolished CLCuKoV-Bur replication. 


\section{Southern blot hybridization for confirmation of viral titer.}

To further confirm our results Southern hybridization was performed on six selected plants and their DNA was isolated. Two control plants infiltrated with virus and purified PCR product of virus from plasmid were used as positive control. Non-infiltrated plant DNA was used as negative control. Probe was developed using CLCuKoV-Bur as template with CLCV1/CLCV2 primers. The results of Southern blot hybridization showed that there is no intact virus found in transgenic $N$. benthamiana plants as shown in Fig. 7. Positive sample in lane 1 is PCR positive which indicate that the probe is working. In lane 2, DNA from the control non-infiltrated plant showed no hybridization with the probe. Lane 3, 10 were genomic DNA of virus infiltrated plants hybridized with the probe. Lanes 4-9 are the transgenic plants harboring the construct NN3 infiltrated with CLCuKoV-Bur showing no hybridization with probe. Southern hybridization along with PCR results indicated that the viral titer in transgenic plants is almost none or too low to be detected by either technique.

\section{Discussion}

Geminiviruses inflict huge crop losses and pose a great threat to food security [17]. Different strategies, like protein mediated resistance, RNA mediated resistance, host derived resistance etc, have been developed to tackle this pathogen but these strategies failed due to the high rate of evolution and recombination of a virus [1]. The virus is able to modify its genome quickly and counter these strategies [4]. In past, different approaches have been followed to create resistance against plant DNA viruses. For example, Pathogen derived resistance (PDR) against Tomato yellow leaf curl Sardinia virus (TYLCSV) by targeting the Rep protein has been developed. This resistance was challenged, and the transgene was silenced by virus exploiting its own defense mechanism known as virus induced gene silencing (VIGS; [16]). Similar results were observed for Bean golden mosaic virus (BGMV) where resistance against the virus was created by targeting the coat protein. Moreover, mutating a Rep gene was used to confer resistance against BGMV but it was again dependent on the viral titer i.e. when the viral titer was higher the resistance mechanism failed to develop [8]. Additionally, Artificial Zinc finger Protein (AZP) was used to target IR of Beet severe curly top virus (BSCTV; [24]). Furthermore, it was observed that zinc finger nucleases (ZFN) performed better than AZP as they not only block a virus binding site but also cleave the viral genome. Transcription activator like effectors (TALEs) have been reported to provide resistance against Tomato yellow leaf curl China virus (TYLCCNV), Tobacco curly shoot virus (TbCSV) and Tomato leaf curl Yunnan virus [5], but these TALE nucleases were not yet known for developing resistance against DNA viruses due to cost and difficulty [28].

The CRISPR-Cas9 system identified in bacteria and archaea provided molecular immunity to fend off the invading phages. This system provides an opportunity for bioengineers to manipulate this system which could then be used to edit or modify genomes, and regulate gene expression and epigenome manipulation. Therefore, this system can be harnessed for genome engineering and to create molecular resistance against DNA viruses by targeting highly conserved regions of the virus or targeting host genes Loading [MathJax]/jax/output/CommonHTML/jax.js y, we have employed CRISPR-Cas9 to selectively target the 
highly conserved IR region of CLCuKoV-Bur. Our data showed that CRISPR-Cas9 system can initiate molecular interference against plant DNA viruses.

In this study, we observed the most efficient virus interference by targeting IR region of CLCuKoV-Bur simultaneously at two (gRNA1 and gRNA2) points. Our results are consistent and in agreement with other studies. For example, Ali et al. [2] have demonstrated viral interference against CLCuKoV by targeting coding (coat protein and RCRII domain of replication associated protein) and non-coding (IR) regions. Their finding suggests that targeting IR regions would provide better interference as compared to coding regions. However, all the results were obtained in transient assay. Here we have developed transgenic lines and challenged them with CLCuKoV-Bur/CLCuMB. Similar conclusions were drawn when CRISPRCas 9 was used against Cotton Leaf curl Multan virus [28].

Our research study provides insight into the exploitation of the CRISPR-Cas9 system as a successful tool for DNA virus interference. It has been shown that targeting highly conserved IR at multiple sites following a multiplex approach can provide almost complete resistance against CLCuKoV-Bur strain. Since, we were unable to detect any intact virus using gene specific and virus specific primers; or by Southern hybridization. There are multiple possibilities for not detecting intact virus particles; the repair process might result in variants incapable of replication, or more likely, amplicons with long deletions would also be incapable of replication. The latter explanation seems to be most relevant because this IR region also contains a bidirectional promoter region. By disrupting this region there is a high possibility to restrain virus replication. Our findings are in agreement with other studies [2] in which they have shown that virus variants having modifications in IR were unable to replicate.

It is worth noting that different approaches; targeting coat protein, Replication associated protein and IR at the same time using a multiplex approach, as well as different gRNAs and delivery systems can be used to improve virus interference. Further studies are needed to reveal the molecular underpinnings involved in virus-host interaction so more targets can be chosen and susceptible genes can be targeted that will result in enhanced immunity against these viruses.

\section{Conclusions}

Our results show that targeting IR following multiplex CRISPR-Cas9 approach can provide highly selective and promising interference against CLCuKoV-Bur.

\section{Declarations}

\section{Acknowledgments}

This material is based upon work supported by the "Pak-US cotton productivity enhancement program" of the International Center for Agricultural Research in the Dry Areas (ICARDA) funded by United States Department of Agriculture (USDA), Agricultural Research Service (ARS), under agreement No. 58-6066-7- 
the author(s) and do not necessarily reflect the views of the USDA or ICARDA. The work was partially funded by International research initiative program (IRSIP) by Higher education commission (HEC) Pakistan.

\section{Compliance with Ethical Standards}

Conflict of Interest

The authors declare that they have no conflict of interest.

Human and animals rights

The research did not involve any studies with human participants or animals performed by any of the authors.

\section{References}

1. Ali I, Amin I, Briddon RW, Mansoor S (2013) Artificial microRNA-mediated resistance against the monopartite begomovirus Cotton leaf curl Burewala virus. Virol J 10:231

2. Ali Z, Ali S, Tashkandi M, Zaidi SS, Mahfouz MM (2016) CRISPR/Cas9-Mediated Immunity to Geminiviruses: Differential Interference and Evasion. Sci Rep 6:26912

3. Amrao L, Amin I, Shahid MS, Briddon RW, Mansoor S (2010) Cotton leaf curl disease in resistant cotton is associated with a single begomovirus that lacks an intact transcriptional activator protein. Virus Res 152:153-163

4. Briddon RW, Akbar F, lqbal Z, Amrao L, Amin I, Saeed M, Mansoor S (2014) Effects of genetic changes to the begomovirus/betasatellite complex causing cotton leaf curl disease in South Asia post-resistance breaking. Virus Res 186:114-119

5. Cheng X, Li F, Cai J, Chen W, Zhao N, Sun Y, Guo Y, Yang X, Wu X (2015) Artificial TALE as a convenient protein platform for engineering broad-spectrum resistance to begomoviruses. Viruses 7:4772-4782

6. Collinge DB, Jorgensen HJ, Lund OS, Lyngkjaer MF (2010) Engineering pathogen resistance in crop plants: current trends and future prospects. Annu Rev Phytopathol 48:269-291

7. Doyle JJ, Doyle JL (1990) Isolation of plant DNA from fresh tissue. Focus 12:13-15

8. Faria JC, Albino MM, Dias BB, Cançado LJ, da Cunha NB, Silva LdM, Vianna GR, Aragao FJ (2006) Partial resistance to Bean golden mosaic virus in a transgenic common bean (Phaseolus vulgaris L.) line expressing a mutated rep gene. Plant Sci 171:565-571

9. Fauquet CM, Bisaro DM, Briddon RW, Brown JK, Harrison BD, Rybicki EP, Stenger DC, Stanley J (2003) Revision of taxonomic criteria for species demarcation in the family Geminiviridae, and an updated list of begomovirus species. Arch Virol 148:405-421 
10. Hussain M, Mansoor S, Amin I, Iram S, Zafar Y, Malik KA, Briddon RW (2003) First report of cotton leaf curl disease affecting chili peppers. New Disease Reports [http://www.bspp.org.uk/ndr/] Volume 7.

11. Ilyas M, Amin I, Mansoor S, Briddon RW, Saeed M (2010) In: Emerging Geminiviral Diseases and their Management, pp. 1-36, Editors: P. Sharma, R. K. Gaur and M. Ikegami, 2010 Nova Science Publishers, Inc. (ISBN: 978-1-61668-620-8). .

12. Iqbal Z, Sattar MN, Shafiq M (2016) CRISPR/CAS9: A TOOL TO CIRCUMSCRIBE COTTON LEAF CURL DISEASE. Frontiers in Plant Science 7:475

13. Ji X, Si X, Zhang Y, Zhang H, Zhang F, Gao C (2018) Conferring DNA virus resistance with high specificity in plants using virus-inducible genome-editing system. Genome Biol 19:197

14. Khan MZ, Amin I, Hameed A, Mansoor S (2018) CRISPR-Cas13a: Prospects for Plant Virus Resistance. Trends Biotechnol

15. Khan MZ, Haider S, Mansoor S, Amin I (2019) Targeting Plant ssDNA Viruses with Engineered Miniature CRISPR-Cas14a. Trends Biotechnol

16. Lucioli A, Noris E, Brunetti A, Tavazza R, Ruzza V, Castillo AG, Bejarano ER, Accotto GP, Tavazza M (2003) Tomato yellow leaf curl Sardinia virus Rep-derived resistance to homologous and heterologous geminiviruses occurs by different mechanisms and is overcome if virus-mediated transgene silencing is activated. J Virol 77:6785-6798

17. Mansoor S, Amin I, Iram S, Hussain M, Zafar Y, Malik KA, Briddon RW (2003) The breakdown of resistance in cotton to cotton leaf curl disease in Pakistan. New Disease Reports 52:784

18. Nahid N, Amin I, Briddon RW, Mansoor S (2011) RNA interference based resistance against a legume Mastrevirus. Virol J 8:499

19. Nawaz-ul-Rehman MS, Fauquet CM (2009) Evolution of geminiviruses and their satellites. FEBS Lett 583:1825-1832

20. Ran FA, Hsu PD, Wright J, Agarwala V, Scott DA, Zhang F (2013) Genome engineering using the CRISPR-Cas9 system. Nat Protoc 8:2281

21. Sambrook J, Frisch EF, Maniatis T (1989) Molecular Cloning: A Laboratory Manual. Cold Spring Harbor Laboratory Press, New York

22. Sattar MN, Kvarnheden A, Saeed M, Briddon RW (2013) Cotton leaf curl disease - an emerging threat to cotton production worldwide. Journal of General Virology 94:695-710

23. Sattar MN, lqbal Z, Tahir MN, Ullah S (2017) The Prediction of a New CLCuD Epidemic in the Old World. Frontiers in Microbiology 8

24. Sera T (2005) Inhibition of Virus DNA Replication by Artificial Zinc Finger Proteins. J Virol 79:26142619

25. Shafiq M, Iqbal Z, Ali I, Abbas Q, Mansoor S, Briddon RW, Amin I (2017) Real-time quantitative PCR assay for the quantification of virus and satellites causing leaf curl disease in cotton in Pakistan. $J$ Virol Methods 248:54-60

Loading [MathJax]/jax/output/CommonHTML/jax.js 
26. Shahid MS, Mansoor S, Briddon RW (2007) Complete nucleotide sequences of cotton leaf curl Rajasthan virus and its associated DNA beta molecule infecting tomato. Arch Virol 152:2131-2134

27. Van Der Oost J, Westra ER, Jackson RN, Wiedenheft B (2014) Unravelling the structural and mechanistic basis of CRISPR-Cas systems. Nature reviews Microbiology 12:479

28. Yin K, Han T, Xie K, Zhao J, Song J, Liu Y (2019) Engineer complete resistance to Cotton Leaf Curl Multan virus by the CRISPR/Cas9 system in Nicotiana benthamiana. Phytopathology Research 1:9

29. Zerbini FM, Briddon RW, Ali Idris, Martin DP, Moriones E, Navas-Castillo J, Rivera-Bustamante R, Roumagnac P, Varsan A (2017) ICTV Virus Taxonomy Profile: Geminiviridae. J Gen Virol 89

30. Zhao Y, Dai Z, Liang Y, Yin M, Ma K, He M, Ouyang H, Teng C-B (2014) Sequence-specific inhibition of microRNA via CRISPR/CRISPRi system. Scientific Reports 4:3943

\section{Figures}

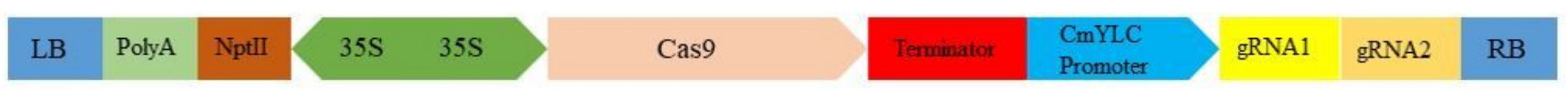

\section{Figure 1}

Schematic diagram of NN3 construct. Showing promoters, selection gene, gRNAs, Cas9 and terminator in between left and right border.

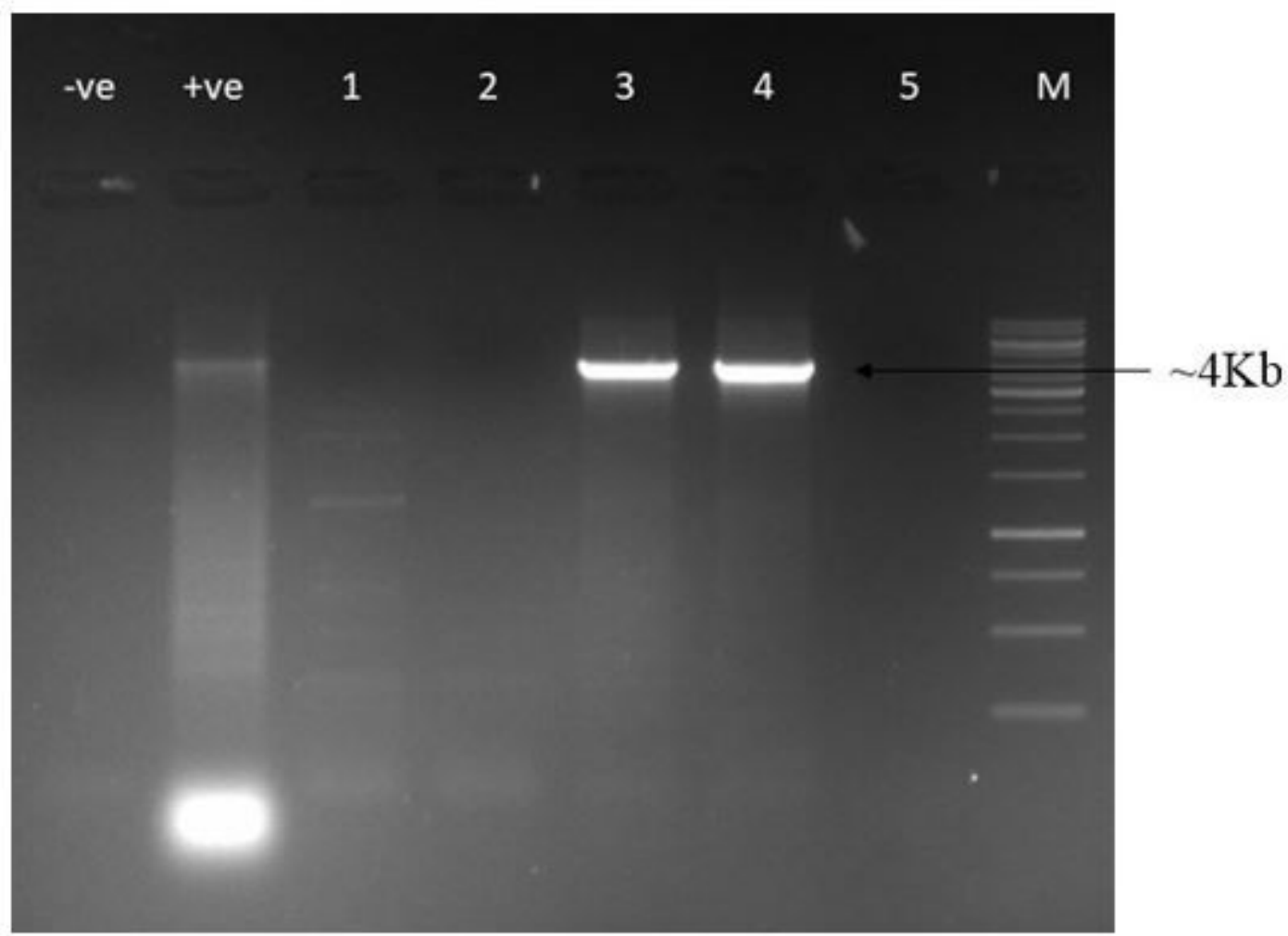


Confirmation of full length Cas9 through PCR using full length Cas9 primers (Cas9-F and Cas9-R). 3 and 4 lane showing presence of Cas9. GeneRuler 1 kb DNA ladder has been used as marker

$\mathbf{A}$

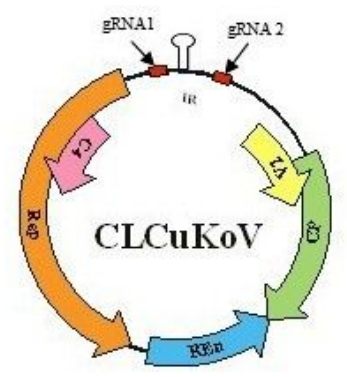

B

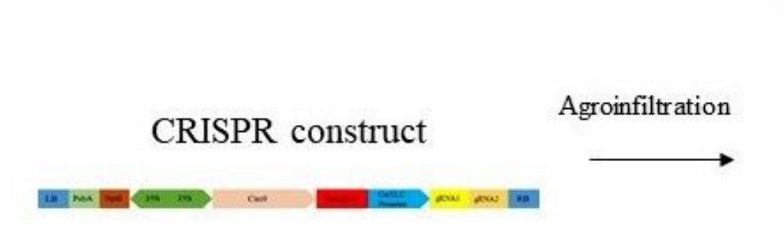

Infectivity assay

C

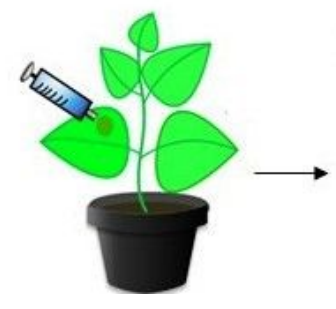

DNA isolation
gRNA1: 5' GAAATTCAAATTCCACTTTG 3' gRNA2: 5' GGGCCCACAAAAAAATCGCG 3'

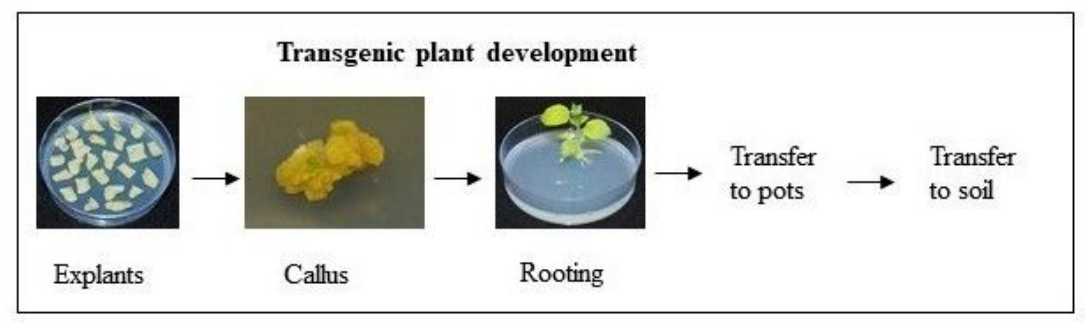

\section{Figure 3}

Development and analysis of transgenic plants with CRISPR construct- (A) gRNAs designed on intergenic region of CLCuKoV-Bur in red square and the sequence of two gRNAs. (B) Agrobacterium mediated transformation in N. benthamiana plants and development of transgenic plants. (C) Infectivity assay and analysis of transgenic plants. 


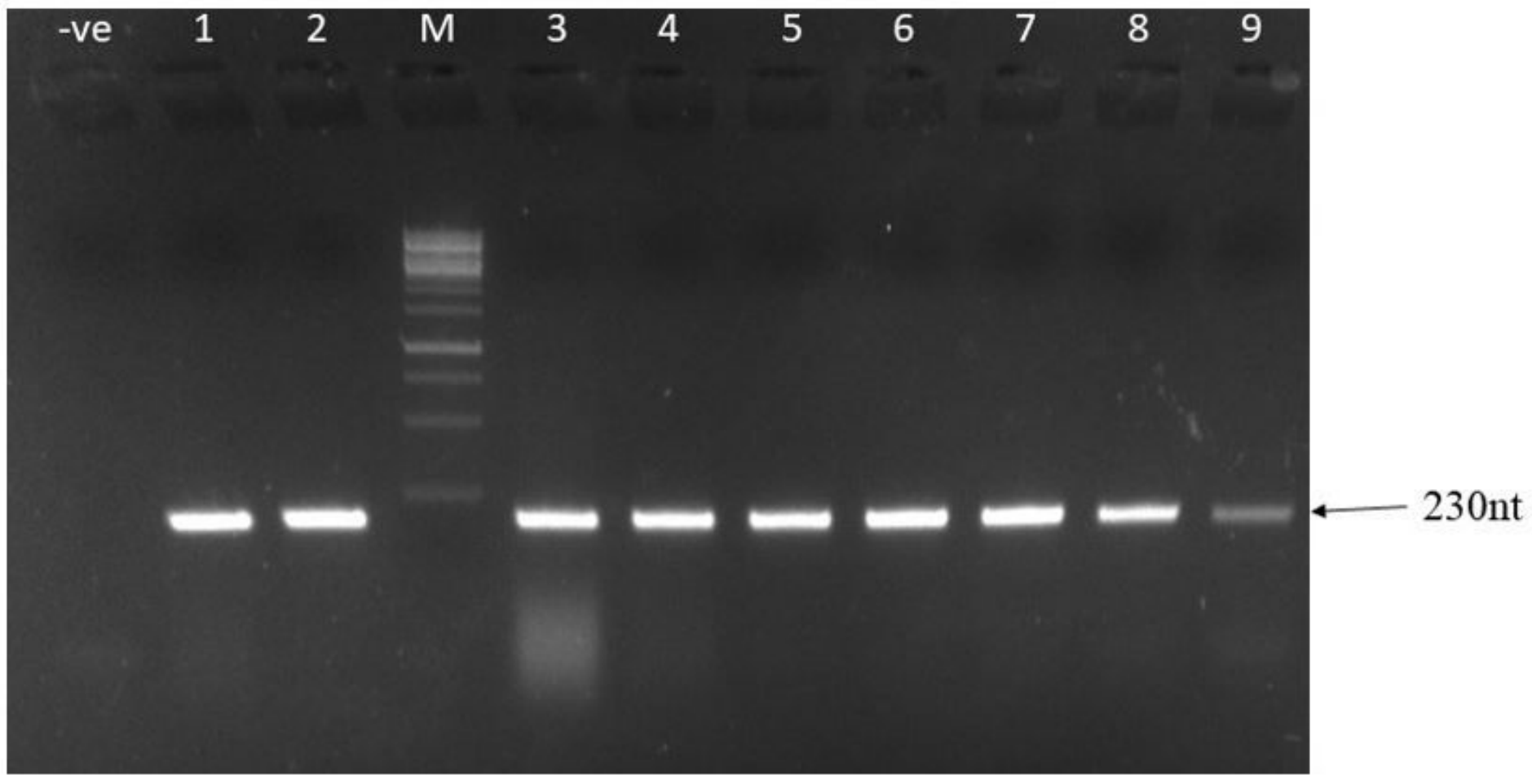

Figure 4

Confirmation of gRNA cassette in transgenic plants through PCR using specific primers (NN-F and NN-R) for amplification of gRNA cassette. First lane is negative PCR 4th lane is marker and sample 1-9 showing presence of gRNA.

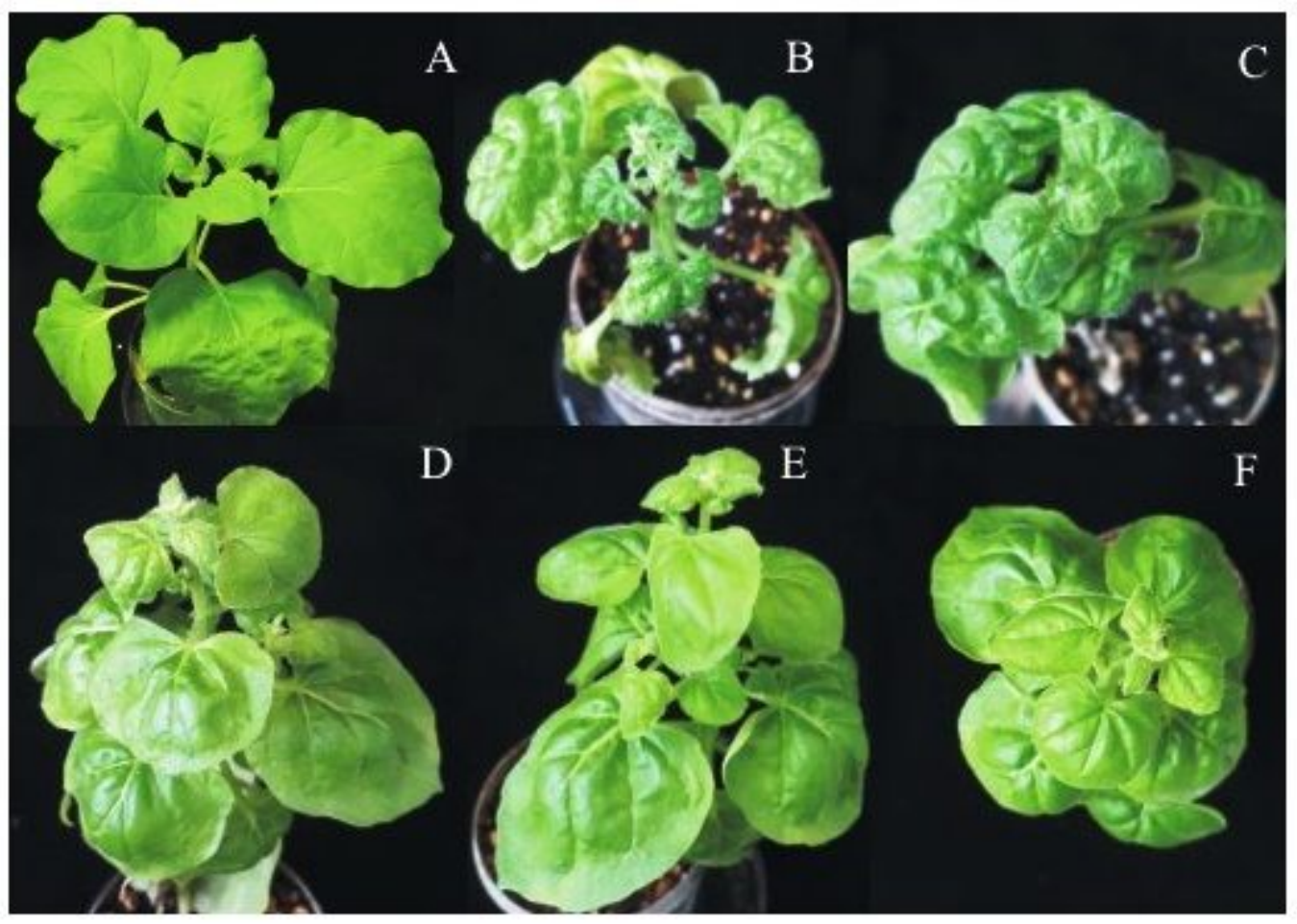

\section{Figure 5}


Virus infiltrated control and transgenic plants of N. benthamiana (A) Control plant (B) Control plant infiltrated with CLCuKoV-Bur/CLCuMB (C) control plant infiltrated with CLCuKoV (D, E) transgenic plants infiltrated with CLCuKoV-Bur. (F) transgenic plant infiltrated with CLCuKoV-Bur/CLCuMB.

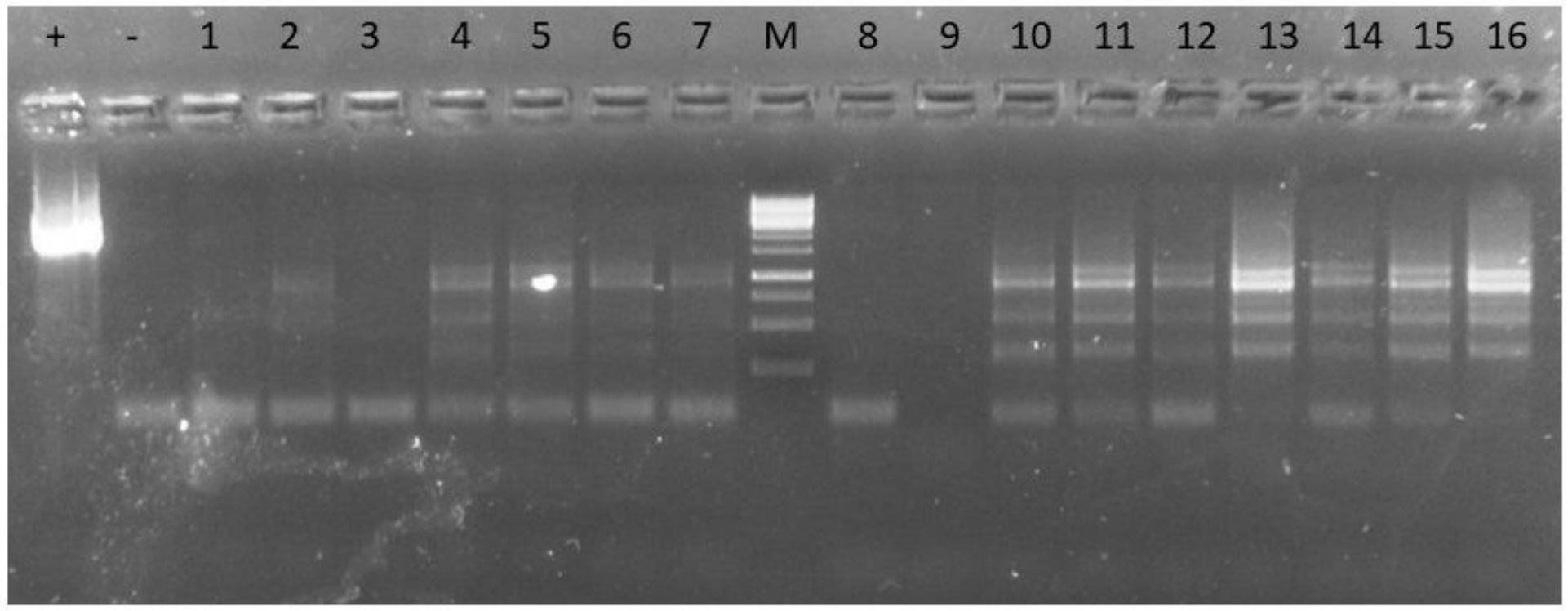

\section{Figure 6}

Results of PCR showing no intact virus amplified though universal primers in virus infiltrated transgenic plants. Lane 1 is positive (non-transgenic infected plant) PCR amplification begomovirus, lane 2 is negative PCR, 1-16 are PCR amplification from virus infiltrated transgenic plants using universal begomovirus primers. No intact virus was found. 


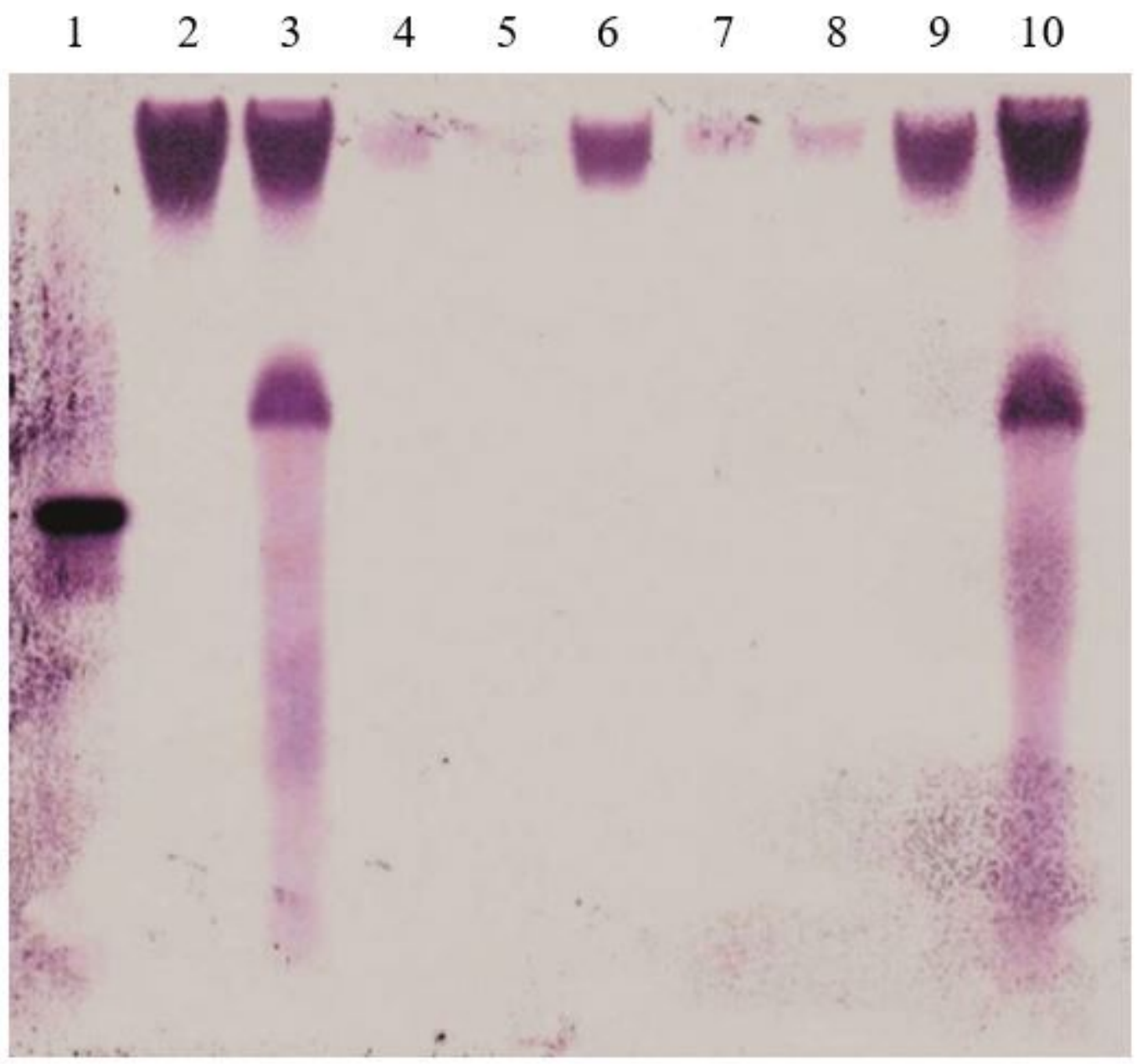

\section{Figure 7}

Southern blot hybridization for the detection of CLCuKoV-Bur using DNA isolated from transgenic plants (lanes 4-9). Lane 1 containing PCR positive control DNA, lane 2 negative control DNA (Non-infiltrated N. benthamiana plant), lanes 3 and 10 with DNA isolated from wild-type N. benthamiana virus inoculated plants. 